\title{
A study on the difference between two types of mountaineering outerwear in a cold, wet and windy environment
}

\author{
Li-Chu Wang ${ }^{*}$, Hsien-Chen Chou, Gwo-Tsuen Jou \\ From 15th International Conference on Environmental Ergonomics (ICEE XV) \\ Portsmouth, UK. 28 June - 3 July 2015
}

\section{Introduction}

For mountaineering, the outer or protective layer of clothing system is especially important for extremely environment. Generally, a breathable barrier embedded in the layered fabric will be used to prevent rain or snow from outside and let the body moisture diffused into air. There are two types of membrane, one is hydrophobic (HPO) and the other is hydrophilic (HPI). A considerable amount of studies claimed that water vapor transport through HPI polymers is highly influenced by the test conditions [1]; in non-isothermal test, the clothing systems incorporating HPI polymers are improved to greater amounts than those incorporating microporous polymers [2]; some experimental results further point out that the water vapor transfer rate of porous polyurethane laminated fabric was greater under isothermal conditions whilst the water vapor transfer rate of HPO laminated fabrics was greater under nonisothermal conditions, especially when a fabric contains more condensation [3]; and, with the use of hot plate and sweating arm system, an EMPA study showed the hydrophilicity and condensation have little effect on effective water vapor resistance of multilayer textile combination in $20{ }^{\circ} \mathrm{C}$ but become larger with decreasing outside temperature [4]. In our previous study, the difference between the microstructure of PTFE and the hydrophilicity of PU affects the comfort properties of leisure wearing especially in mild and cool temperature, water vapor resistance testing (Ret), EMPA sweating torso wearing trial simulation, and subjective wearing trials were conducted. The HPO is better in Ret test, though the HPI is slightly better in the non-isothermal

\footnotetext{
* Correspondence: IcWang.0269@ttri.org.tw

Department of Testing and Certification, Taiwan Textile Research Institute, Taiwan, Republic of China
}

state. While the subjective wear trial showed no significant difference [5]. So this extended study aimed to determine the comfort properties by a wear trial in an extremely environment.

\section{hods} previous study [5] and with beanie, scarf, and gloves), performed the same protocol involved in 15 minutes of sitting without rain, and 20 minutes of walking $\left(1.5 \mathrm{~km} \cdot \mathrm{h}^{-1}\right.$ at $5 \%$ gradient) on treadmill, with rain. The environmental conditions were maintained at: $5 \pm 1{ }^{\circ} \mathrm{C}, 50 \pm 3 \% \mathrm{RH}, 150 \pm$ $10 \mathrm{~mm} . \mathrm{h}^{-1}$ rainfall, $3 \pm 0.5 \mathrm{~m} . \mathrm{s}^{-1}$ wind speed. Skin tem$\left(\mathrm{S}_{\mathrm{C}}\right)$ and perceived comfort were recorded for each participant.

\section{Results}

The results of $T_{S}$ and $T_{M}$ showed HPI was lower at the beginning and up to 0.7 and $1.3^{\circ} \mathrm{C}$ higher at the follow-up stage of the experiment. Thermal perceptions revealed similar trend. $\mathrm{H}_{\mathrm{M}}$ demonstrated similar results of $\mathrm{HPO}$ and HPI, while subjective dampness showed 0.5 grade dryer of HPI in walking period. The $\mathrm{S}_{\mathrm{C}}$ weight was $21.2 \mathrm{~g}$ and $17.7 \mathrm{~g}$ for HPO and HPI respectively. The declines of $\mathrm{T}_{\text {IR }}$ were very similar.

\section{Discussion}

Both for $\mathrm{T}_{\mathrm{S}}$ and $\mathrm{T}_{\mathrm{M}}$, HPI and HPO crossed each other during walking, and HPI revealed higher warmth keeping ability. $\mathrm{S}_{\mathrm{C}}$ weight was $3.5 \mathrm{~g}$ lower and the dampness perception was slightly drier for HPI. 


\section{Conclusion}

HPI demonstrated slightly colder at the starting point, but had less sweat condensation in the clothing system, and became warmer after walking for about 10 minutes in a cold, wet and windy environment, suggesting that a better comfort was achieved. However, the subjective perspirations were not significant between HPO and HPI outerwear in terms of comfort property.

Published: 14 September 2015

\section{References}

1. Mukhopadhyay A, Midha VK: A Review on Designing the Waterproof Breathable Fabrics Part I: Fundamental Principles and Designing Aspects of Breathable Fabrics. J of Industrial Textile 2008, 37(3):225-262.

2. Gretton JC, et al: Moisture Vapor Transport Through Waterproof Breathable Fabrics and Clothing Systems Under a Temperature Gradient. Textile Res J 1998, 68(12):936-941.

3. Ren YJ, Ruckman JE: Journal of Industrial Textile 2004, 32(3):165-175.

4. Rossi RM, et al: Textile Res J 2004, 74(1):1-6.

5. Lin YW, et al: Proceedings of 13th ICEE 2009, 70-74.

doi:10.1186/2046-7648-4-S1-A91

Cite this article as: Wang et al:: A study on the difference between two types of mountaineering outerwear in a cold, wet and windy environment. Extreme Physiology \& Medicine 2015 4(Suppl 1):A91.

Submit your next manuscript to BioMed Central and take full advantage of:

- Convenient online submission

- Thorough peer review

- No space constraints or color figure charges

- Immediate publication on acceptance

- Inclusion in PubMed, CAS, Scopus and Google Scholar

- Research which is freely available for redistribution

Submit your manuscript at www.biomedcentral.com/submit 